\title{
THE CHROMOSOMAL LOCATION OF THE DWARFING GENE PRESENT IN THE SPRING BARLEY VARIETY GOLDEN PROMISE
}

\author{
W. T. B. THOMAS, W. POWELL AND W. WOOD \\ Scottish Crop Research Institute (Pentlandfield), Rostin, EH25 9RF, U.K.
}

Received 13.xii.83

\section{SUMMARY}

\begin{abstract}
Data from F2 and doubled monoploid populations segregating for major gene markers indicated that the dwarfing gene present in the spring barley varieties Golden Promise and Midas was located on chromosome 7. This was confirmed by the use of a suitable translocation stock, which showed that the gene was located on the short arm of chromosome 7. Single seed descent lines showed that an extra round of recombination was sufficient to break the linkage between the dwarfing gene and the rachilla hair locus. The implications of the use of dwarfing genes in breeding programmes and the strategy for their deployment is discussed.
\end{abstract}

\section{INTRODUCTION}

Lodging is a major cause of yield loss in barley crops under British growing conditions. Shortness of straw is the most important character limiting lodging in barley (Stanca et al., 1979) and dwarfing genes have been extensively used in breeding programmes to shorten straw and hence reduce this problem. One of the most commonly used type of short straw in spring barley is that associated with an erect juvenile growth habit and erect ear carriage. Sources of this gene include the semi-dwarf varieties Golden Promise (a gamma-ray mutant of the variety Maythorpe) and Midas, which was derived from a Golden Promise sister line (Anon., 1982). These varieties and their derivatives have been widely grown in Scotland and their dwarfing gene has often been used in the SCRI spring barley breeding programme. Although a breeder may exploit these dwarfing genes with little knowledge of their genetic control, genetic analysis can aid breeding programmes in several ways. For example, a knowledge of the chromosomal location of the gene may be used to exploit or avoid known linkage relationships. The present investigation was therefore conducted to determine the chromosomal location of the erectoides dwarfing gene (GP ert) present in Golden Promise and its derivatives using progenies from appropriately marked Hordeum vulgare genotypes. A pilot study showed that the dwarfing gene present in Golden Promise was not allelic to either the ert-a, ert-b, ert-c, ert-g or ert-m erectoides loci described by Persson and Hagberg (1969).

\section{Materials AND METHODS}

A number of different techniques were used to locate the GP ert gene.

\section{(i) Genetic markers}

The genetic markers used, their chromosomal locations and symbols used to represent them are given in table 1. Each was a single gene marker, 
TABLE I

Summary of genetic markers, their chromosomal location and gene symbol designations used in linkage tests with the dwarfing gene GP ert

\begin{tabular}{lcc}
\hline \multicolumn{1}{c}{ Character Pair } & Gene Symbol & Chromosome Location \\
\hline Covered vs. naked caryopsis & N vs. $n$ & 1 (Nilan, 1964) \\
Black vs. white pericarp & B vs. b & 5 (Nilan, 1964) \\
Long vs. short haired rachilla & S vs. s & 7 (Nilan, 1964) \\
$\begin{array}{l}\text { DDT susceptibility } \\
\text { vs. resistance }\end{array}$ & Ddt vs. ddt & 7 (Hayes and Rana, 1966) \\
Tall vs. dwarf & GP Ert vs. GP ert & $?$ \\
\hline
\end{tabular}

+ Provisional gene designation.

introduced into the variety Bonus, and was known to be simply inherited. Each stock was crossed with the variety Midas and the resulting F2 progeny was examined for segregation of the marker and the dwarfing gene into the four phenotypic classes expected with independent segregation.

\section{(ii) Doubled monoploids}

Doubled monoploid lines were produced from the Fl of the cross Golden Promise $\times$ Mazurka. This cross will segregate for rachilla hair type and reaction to DDT as well as for the dwarfing gene (Anon., 1982). Variation between these doubled monoploid lines is equivalent to that expected from a backcross of the Fl to the double recessive parent. In the absence of linkage, equal frequencies of the phenotypic classes are expected (Snape and Simpson, 1982). Lines from the cross were assessed for their reaction to DDT by spraying 16 plants from each line with a 0.2 per cent aqueous emulsion of DDT at the 2 leaf stage (Hayes and Rana, 1966). One week later, the plants were scored as being either resistant or susceptible to DDT.

\section{(iii) Translocation stock}

Golden Promise was crossed to the homozygous translocation line T3-7d (supplied by Dr J. Jensen, Ris $\varnothing$ Research Station, Denmark). Translocation stocks have been extensively used in linkage studies and the F2 populations derived from such crosses are expected to segregate in the ratio of 1 normal: 2 heterozygote translocations: 1 homozygote translocation. Since normal and homozygous translocation stocks both have normal levels of fertility and genotypes heterozygous for translocations show marked signs of sterility, a phenotypic ratio of 1 fertile: 1 semi-sterile is expected in the F2 generation. However with close linkage, the frequency of semi-sterile F2 plants is about twice the recombination frequency between the translocation break point and the gene under study (Jensen, 1979). Ten per cent ovule sterility was selected as the point of differentiation between normal and semi-sterile plants.

\section{(iv) Single seed descent lines}

90 random lines were produced from the cross Golden Promise $\times$ Mazurka by the single seed descent method (Goulden, 1939). The lines were 
advanced to the F4 generation and then multiplied before assessment at the F6 generation when the lines were classified into the four phenotypic classes expected with independent segregation.

The experimental material produced by techniques (i), (ii) and (iii) was grown in field experiments at the Murrays farm, East Lothian. Single plants were spaced $5 \mathrm{~cm}$ apart within rows and $22 \mathrm{~cm}$ apart between rows using the NIAE spaced plant seeder. The experiments were netted to prevent bird damage. All the plants were recovered and scored for the expression of the major gene markers, height $(\mathrm{cm})$ and rachis internode length, measured as the length of 10 internodes from the base of kernel 5 (Perssson and Hagberg, 1969). The material produced by technique (iv) was grown in a replicated, randomised small plot yield trial and the plots were scored for juvenile growth habit approximately 6 weeks after sowing and for height before harvest. Seed from the plots was scored for rachilla hair type.

$\chi^{2}$ analyses were performed to detect the presence of linkage. Recombination fractions and their standard errors were calculated using the method of maximum likelihood (Mather, 1957).

\section{Results}

The erectoides dwarfing gene segregating in the various experimental populations was classified on the basis of height and, where possible, juvenile growth habit. Excellent correspondence between these characters was found when both were measured together. Because juvenile growth habit and height are commonly and easily measured by breeders, it was considered appropriate to use these characters to classify the dwarfing gene.

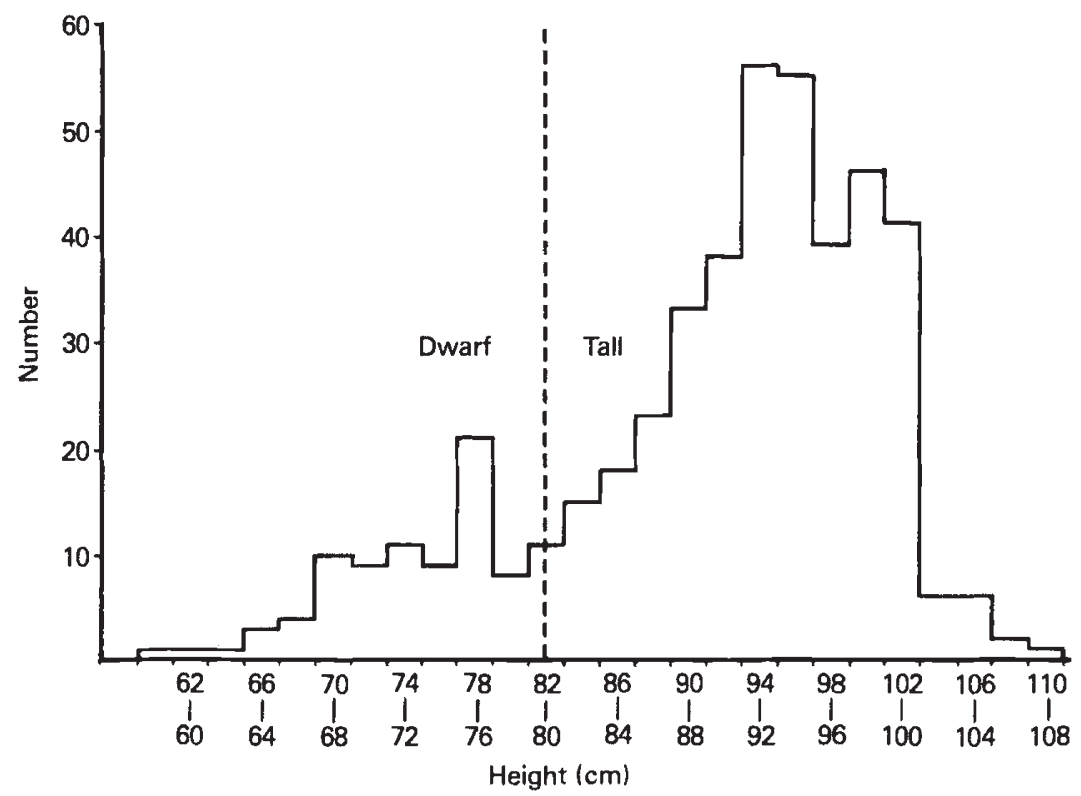

FIG. 1. Frequency distribution of height $(\mathrm{cm})$ in an $F_{2}$ population from the cross short-haired Rachilla $\times$ Midas. 
For illustrative purposes, the frequency distribution of height in the F2 population from the cross short haired rachilla $\times$ Midas is presented in fig. 1. Plants shorter than $82 \mathrm{~cm}$ were classified as possessing the GP ert gene.

The results of the linkage tests for the naked $(N / n)$, black pericarp $(B / b)$ and rachilla hair length (S/s) loci and the GP ert locus are presented in table 2. Only the cross between short haired rachilla and Midas indicated

\section{TABLE 2}

Summary of tests for independant segregation in F2 populations of Midas and genetic markers located on chromosomes 1,5 and 7 of barley

\begin{tabular}{|c|c|c|c|c|c|}
\hline \multicolumn{2}{|c|}{ Naked $\times$ Midas } & \multicolumn{2}{|c|}{ Black Lemma $\times$ Midas } & \multicolumn{2}{|c|}{ Short Haired Rachilla $\times$ Midas } \\
\hline Phenotype & $\begin{array}{l}\text { Observed } \\
\text { frequency }\end{array}$ & Phenotype & $\begin{array}{l}\text { Observed } \\
\text { frequency }\end{array}$ & Phenotype & $\begin{array}{l}\text { Observed } \\
\text { frequency }\end{array}$ \\
\hline GP $E r t / N$ & 136 & GP $E r t / B$ & 181 & GP $E r t / S$ & 251 \\
\hline GP ert/N & 79 & GP ert/B & 70 & GP ert/S & 89 \\
\hline GP $E r t / n$ & 63 & GP Ert/b & 68 & GP $E r t / s$ & 118 \\
\hline GP ert/n & 19 & $\mathrm{GP}$ ert $/ \mathrm{b}$ & 28 & GP ert $/ \mathrm{s}$ & 10 \\
\hline$\chi_{\boldsymbol{P}^{3]}}^{2}$ & $\begin{array}{c}3.82 \\
0.3-0.2\end{array}$ & $\chi_{[P]}^{2}$ & $\begin{array}{c}3 \cdot 38 \\
0 \cdot 5-0 \cdot 3\end{array}$ & $\chi_{\left[P_{P}^{3]}\right.}^{2}$ & $\begin{array}{l}23.68 \\
<0.001\end{array}$ \\
\hline
\end{tabular}

Partioned $\chi^{2}$ analysis of the cross short haired ranchilla $\times$ Midas

\begin{tabular}{lccc}
\hline Source of Variation & df & \multicolumn{1}{c}{$\chi^{2}$} & \multicolumn{1}{c}{$P$} \\
\hline Segregation Ert : ert & 1 & 3.69 & $0.1-0.05$ \\
Segregation S:s & 1 & 1.38 & $0.3-0.2$ \\
Linkage & 1 & 18.61 & $<0.001$ \\
(Total) & 3 & 23.68 & \\
\hline
\end{tabular}

a significant departure from the expected ratio of $9: 3: 3: 1 \quad\left(\chi_{[3]}^{2}=23 \cdot 68\right.$, $P=<0.001)$. This indicates that naked grain and black pericarp are inherited independently from the dwarfing gene while there was significant linkage between the rachilla hair length locus and the dwarfing gene $\left(\chi_{[1]}^{2}=18 \cdot 61\right.$, $P=<0.001$ ) showing that the dwarfing gene locus is located on chromosome 7. A recombination fraction of $0.3039 \pm 0.04065$ was obtained. For all three crosses, there was no significant departure from the expected 3:1 ratio for the loci under study. A number of F3 plants was raised from the short haired rachilla $\times$ Midas cross and scored for juvenile growth habit and rachilla hair length. The results confirmed those obtained from the F2 and that the GP ert gene is inherited as a single recessive gene.

The frequency distribution of height in the doubled monoploid population derived from the F1 of Golden Promise $\times$ Mazurka was used to classify lines into those possessing the dwarfing gene and those not. The four phenotypic classes derived from segregation for both the dwarfing gene and rachilla hair type are given in table 3. For rachilla hair type, there was a significant departure from the $1: 1: 1: 1$ ratio expected on the basis of independent inheritance $\left(\chi_{[3]}^{2}=18 \cdot 24, P=<0.001\right)$. Linkage was again detected $\left(\chi_{[1]}^{2}=14 \cdot 16, P=<0.001\right)$, confirming the results obtained from the F2 data. A recombination fraction of $0 \cdot 3140 \pm 0.0460$ was obtained. This agrees very well with the value estimated from the F2 data. Similarly, for 
TABLE 3

$\chi^{2}$ tests for independent segregation in a doubled monoploid population derived from Fl hybrids of the cross Golden Promise $\times$ Mazurka

\begin{tabular}{|c|c|c|c|c|c|c|c|}
\hline \multicolumn{4}{|c|}{ Rachilla Hair Type } & \multicolumn{3}{|c|}{ DDT Reaction } & \\
\hline Phenotype & \multicolumn{3}{|c|}{ Observed frequency } & Phenotype & \multicolumn{2}{|c|}{ Observed frequency } & \\
\hline GP $E r t / S$ & & 12 & & GP Ert/Ddt & \multicolumn{2}{|c|}{33} & \\
\hline GP ert/S & & 29 & & \multirow{2}{*}{$\begin{array}{l}\text { GP ert/Ddt } \\
\text { GP Ert/ddt }\end{array}$} & \multicolumn{2}{|c|}{14} & \\
\hline GP Ert/s & & 41 & & & \multirow{2}{*}{\multicolumn{2}{|c|}{7}} & \\
\hline GP $\mathrm{ert} / \mathrm{s}$ & & 20 & & $\begin{array}{l}\text { GP Ert/ddt } \\
\text { GP ert } / \text { ddt }\end{array}$ & & & \\
\hline$x_{[3]}^{2}$ & & $18 \cdot 24$ & & \multirow{2}{*}{$\underset{P}{\chi_{[3]}^{2}}$} & \multicolumn{2}{|c|}{$\begin{array}{r}31 \\
22.99\end{array}$} & \\
\hline & & $<0.001$ & & & \multicolumn{2}{|c|}{$<0.001$} & \\
\hline \multicolumn{8}{|c|}{ Partitioned $\chi^{2}$ analysis } \\
\hline \multicolumn{4}{|c|}{ Rachilla Hair Type } & \multicolumn{4}{|c|}{ DDT Reaction } \\
\hline $\begin{array}{l}\text { Source of } \\
\text { variation }\end{array}$ & df & $x^{2}$ & $P$ & $\begin{array}{c}\text { Source of } \\
\text { variation }\end{array}$ & df & $x^{2}$ & $P$ \\
\hline $\begin{array}{c}\text { Segregation } \\
\text { Ert : ert }\end{array}$ & 1 & $0 \cdot 16$ & $0 \cdot 7-0.5$ & $\begin{array}{c}\text { Segregation } \\
\text { Ert }: \text { ert }\end{array}$ & 1 & $0 \cdot 29$ & $0.7-0.5$ \\
\hline $\begin{array}{l}\text { Segregation } \\
\text { S:s }\end{array}$ & 1 & 3.92 & $0.05-0.02$ & $\begin{array}{c}\text { Segregation } \\
\text { Ddt: ddt }\end{array}$ & 1 & 0.95 & $0.5-0.3$ \\
\hline Linkage & 1 & $14 \cdot 16$ & $<0.001$ & Linkage & 1 & $21 \cdot 75$ & $<0.001$ \\
\hline (Total) & 3 & $18 \cdot 24$ & $<0.001$ & (Total) & 3 & 22.99 & $<0.001$ \\
\hline
\end{tabular}

reaction to DDT, there was also a significant departure from the expected $1: 1: 1: 1$ ratio $\left(\chi_{[3]}^{2}=22.99, P=<0.001\right)$. Linkage was the cause of this departure $\left(\chi_{[1]}^{2} \stackrel{=}{=} 21 \cdot 75, P=<0.001\right)$, giving a recombination fraction of $0 \cdot 2471 \pm 0.0468$. The map distance between the DDT and short haired rachilla loci is $61 \cdot 8 \pm 2.8$ centimorgans (Jensen, 1982). Our results are consistent with this report and suggest that the GP ert gene is located between the rachilla hair type and DDT reaction loci. Whilst the segregations of the GP ert and DDT reaction genes did not deviate significantly from the expected 1:1 ratio, the deviation of the rachilla hair gene was significant at the borderline level, possibly due to mis-classification or some slight effect of differential survival during greenhouse multiplication.

The association of the dwarfing gene with chromosome 7 was further verified by crossing Golden Promise with the translocation stock T3-7d. Classification of plants within the population containing the dwarfing gene indicated a significant shortage of semi-fertile plants. The ratio of fertile to semi-fertile plants was $65: 12, \chi_{[1]}^{2}=36.48, P=<0.001$. A recombination fraction of 0.078 between the dwarfing gene and the translocation break point was obtained. The break-point of translocation T3-7d is located on the short arm of chromosome 7, proximal to the satellite, thus indicating that the dwarfing gene must be located on the short arm of chromosome 7 (Persson and Hagberg, 1969). Persson (1969) estimated the recombination fraction between the break-point of T3-7d and the rachilla hair type locus as $0.257 \pm 0.033$. Hence, the estimates from the F2, doubled monoploid and translocation stock data all locate the GP ert gene in the same region of the short arm of chromosome 7. 
Single seed descent lines derived from F2 seed of Golden Promise $\times$ Mazurka provide an opportunity to examine the role of an extra round of recombination on the linkage between the dwarfing gene and the rachilla hair locus. The expected and observed phenotypic classes are presented in table 4. They are derived from F2 gametogenesis, as the measurements were made on F6 bulk plots which were derived from a single F3 seed. The observed phenotypic classes do not deviate significantly from those expected with independent segregation $\left(\chi_{[3]}^{2}=2 \cdot 54, P=0 \cdot 5-0 \cdot 3\right)$. Any linkage between the dwarfing gene and the rachilla hair locus has therefore been broken following the extra round of recombination.

TABLE 4

Phenotypic classes obtained in F6 bulk lines from the cross Golden Promise $\times$ Mazurka

\begin{tabular}{ccc}
\hline Phenotype & Observed frequency & Expected frequency \\
\hline GP Ert/S & 34 & $35 \cdot 16$ \\
GP ert $/$ S & 26 & 21.09 \\
GP Ert/s & 16 & 21.09 \\
GP $e r t / s$ & 14 & 12.66 \\
$\chi^{2}$ & 2.54 & \\
$P$ & $0.5-0.3$ & \\
\hline
\end{tabular}

+ With independent segregation.

\section{Discussion}

It is already known that two dwarfing gene loci, ert-n and ert-g, are located on the long arm of chromosome 7 . These erectoides (ert) mutants generated and mapped by Persson and Hagberg (1969) are characterised by short rachis internodes. The present study has located the erectoides dwarfing gene present in Golden Promise and Midas on the short arm of chromosome 7 and the chromosomal location of GP ert would indicate that it is different from the erectoides mutants described by Persson and Hagberg (1969). In fact, one of the main diagnostic differences between Golden Promise and Midas is that Midas has medium length rachis internodes (Anon., 1982). Furthermore, in this study, it was possible to identify F2 plants from both Golden Promise and Midas crosses possessing the GP ert gene together with long rachis internodes. Hence, the GP ert gene does not appear to be associated with short rachis internodes. Hanson et al. (1981) suggest that the dwarfing genes in Golden Promise and Midas are different, based on tests of insensitivity to gibberellic acid. This difference does not appear to be related to a difference in the gene controlling plant height and juvenile growth habit. Indeed, the F1 of Golden Promise $\times$ Midas does differ significantly from either parent with respect to these two characters.

In a plant breeding context, the main area of interest is in the consequences of using a particular dwarfing gene in a breeding programme. However, data presented in this paper indicate that the breeding strategy adopted will also influence the outcome. For example, cycles of single seed descent may provide sufficient rounds of recombination for any undesirable linkages 
between the dwarfing gene and characters of agronomic importance to be broken. Conversely, desirable linkages may be preserved by early selection of the dwarfing gene. Snape and Simpson (1982) used doubled monoploid lines produced by the Hordeum bulbosum method to investigate the pleiotropic effects of the "denso" dwarfing gene. This gene, which is present in the variety Maris Mink, caused a reduction in plant height, delayed ear emergence, reduced grain size and decreased yield. However the doubled monoploids were derived from $\mathrm{Fl}$ plants and the single round of recombination may have been insufficient to break any linkage groups. Barley provides an unique opportunity to distinguish between pleiotropic effects of dwarfing genes and any linkage effects. Single seed descent lines and F1 derived doubled monoploid populations will be examined to see if any character associations with the dwarfing gene can be broken by providing further opportunities for recombination.

Acknowledgements. The authors acknowledge the value of discussions with Dr A. M. Hayter, Dr P. D. S. Caligari and J. S. Swanston. We also acknowledge the technical assistance of Miss E. Baird, G. R. Drabble, Mrs J. I. Gordon and Mrs M. McGuigan.

\section{REFERENCES}

ANON. 1982. Detailed description of varieties of wheat, barley, oats and rye. 1982. National Institute of Agricultural Botany, Cambridge.

goulden, C. H. 1939. Problems in plant selection. In Proceedings of the Seventh International Genetics Congress. Cambridge University Press.

HANSON, P. R., MCVITTIE, J. A. AND SMALLEY, J. L. 1980. Seedling response to exogenous gibberelic acid in spring barley. Z. Pflanzenzucht., 84, 115-121.

HAYES, J. D. AND RANA, M. S. 1966. Genetic resistance to DDT in Hordeum. 1. Linkage studies in diploid barley. Heredity, 21, 581-593.

JENSEN, J. 1979. Location of a high lysine gene and the DDT resistance gene on barley chromosome 7. Euphytica, 28, 47-56.

JENSEN, J. 1982. Construction of a barley chromosome 7 linkage map. In Proceedings of the Fourth International Barley Genetics Symposium, Edinburgh, 1981. Edinburgh University Press.

MATHER, K. 1957. The measurement of linkage in heredity. Methuen's monographs on biological subjects. Methuen and Co., London.

NILAN, R. A. 1964. The cytology and genetics of barley 1951-1962. Monograph Supplement No. 3., Washington State University.

PERSSON, G. 1969. An attempt to find suitable genetic markers for dense ear loci in barley 1. Hereditas, 62, 25-88.

PERSSON, G. AND HAGBERG, A. 1969. Induced variation in quantitative characters in barley. Morphology and cytogenetics of erectoides mutants. Hereditas, 61, 115-178.

SNAPE, J. W. AND SIMPSON, E. 1982. The use of doubled haploid lines for genetical analysis in barley. In Proceedings of the Fourth International Barley Genetics Symposium, Edinburgh, 1981. Edinburgh University Press.

STANCA, A. M., JENKINS, G. AND HANSON, P. R. 1979. Varietal responses in spring barley to natural and artificial lodging and to a growth regulator. J. Agric. Sci. Camb., 93, 449-456. 